\title{
Temporal Trends and Patient Characteristics Associated With Drug Utilisation After First-Ever Stroke: Insights From Chronic Disease Registry Data in Singapore
}

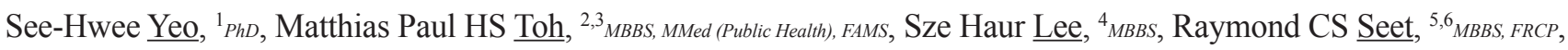
Lai Yin Wong, ${ }^{2}$ BA (Econ \& Stats), MMed (TCM), MPH, Wai-Ping Yau, ${ }^{1}$ PhD

\begin{abstract}
Introduction: Data on drug utilisation among stroke patients of Asian ethnicities are lacking. The objectives of the study were to examine the temporal trends and patient characteristics associated with prescription of thrombolytic, antithrombotic and statin medications among patients with first-ever stroke. Materials and Methods: First-ever ischaemic and haemorrhagic stroke patients admitted to 2 Singapore tertiary hospitals between 2010-2014 were included. Data were extracted from the National Healthcare Group Chronic Disease Management System. Association between drug utilisation and admission year, as well as characteristics associated with drug use, were explored using multivariable logistic regression. $\underline{\text { Results: }}$ There was an increasing trend in the combined use of all 3 guideline medications in ischaemic stroke patients $(P<0.001)$-specifically thrombolytic agents $(P<0.001)$, oral antithrombotics $(P=0.002)$ and statins $(P=0.003)$ at discharge. Among antithrombotics, the use of clopidogrel $(P<0.001)$ and aspirinclopidogrel $(P<0.001)$ had increased, whereas prescription of dipyridamole $(P<0.001)$ and aspirin-dipyridamole $(P<0.001)$ had declined. For statins, the increase in atorvastatin prescription $(P<0.001)$ was accompanied by decreasing use of simvastatin $(P<0.001)$. Age, ethnicity and certain comorbidities (hyperlipidaemia, atrial fibrillation and chronic kidney disease) were associated with the combined use of all 3 guideline medications $(P<0.05)$. In haemorrhagic stroke, prescription of statins at discharge were comparatively lower. Conclusion: This study reveals changes in prescription behaviour over time in a multiethnic Asian population with first-ever stroke. Patient characteristics including younger age, Malay ethnicity and certain comorbidities (i.e. hyperlipidaemia, atrial fibrillation) were associated with the combined use of all 3 guideline medications among ischaemic stroke patients.
\end{abstract}

Ann Acad Med Singapore 2020;49:137-54

Key words: Antithrombotics, Asian, Statins, Thrombolytic agents

\section{Introduction}

Medical professional organisations such as the American Heart Association (AHA), American Stroke Association (ASA) and American College of Cardiology (ACC), have published evidence-based clinical practice guidelines recommending pharmacotherapy to improve stroke outcomes. ${ }^{1-5}$ Three medication classes, namely thrombolytic agents, antithrombotics and statins, are generally recommended for ischaemic stroke, ${ }^{1-3}$ but not for haemorrhagic stroke unless specifically indicated for other comorbidities. ${ }^{4,5}$
Despite publication of these guidelines, limited data are available on physician and patient adherence to these practice recommendations. ${ }^{6}$ Previous studies have indicated a wide heterogeneity in medication use and adherence in different populations ${ }^{7-10}$ and it is unclear whether international recommendations are closely adhered to among Asians. Furthermore, sparse data are available on the drug prescription patterns among physicians caring for stroke patients in Singapore. One local study had found that most ischaemic stroke patients with atrial fibrillation (AF) were not on appropriate anticoagulation, indicating likely

${ }^{1}$ Department of Pharmacy, Faculty of Science, National University of Singapore, Singapore

${ }^{2}$ Chronic Disease Epidemiology, Population Health, National Healthcare Group, Singapore

${ }^{3}$ Saw Swee Hock School of Public Health, National University of Singapore, Singapore

${ }^{4}$ Department of Neurology, National Neuroscience Institute (Tan Tock Seng Hospital Campus), Singapore

${ }_{5}^{5}$ Department of Medicine, Yong Loo Lin School of Medicine, National University of Singapore, Singapore

${ }^{6}$ Division of Neurology, University Medicine Cluster, National University Health System, Singapore

Addresses for Correspondence: Dr Matthias Paul Toh Han Sim, Chronic Disease Epidemiology, Population Health, National Healthcare Group, 3 Fusionopolis

Link, \#03-08, Nexus@one-north (South Lobby), Singapore 138543; Dr Yau Wai-Ping, Department of Pharmacy, Faculty of Science, National University of

Singapore, 18 Science Drive 4, Singapore 117543.

Email: matthias_toh@nhg.com.sg; phaywp@nus.edu.sg 
under-utilisation. ${ }^{11}$ Hence, this study aimed to examine the temporal trends in prescription of thrombolytic agents, antithrombotics and statins during hospitalisation or at discharge among first-ever stroke patients admitted to 2 tertiary hospitals between 2010-2014, and to explore patient characteristics associated with drug utilisation.

\section{Materials and Methods}

\section{Data Source and Study Population}

Data were extracted from the National Healthcare Group (NHG) Chronic Disease Management System (CDMS). NHG is one of the public healthcare clusters in Singapore, providing both acute and primary care services through its network of clinics, hospitals and national specialty centres. CDMS is an enterprise-wide registry containing clinical and administrative information. ${ }^{12}$ We used data from 2 tertiary hospitals in the NHG cluster, including one which houses the national specialty centre for neurosciences. The study protocol was approved by the NHG Domain Specific Review Board (reference number: 2015/01222) which waived the need for written informed consent.

Patients with first-ever ischaemic or haemorrhagic (intracerebral or subarachnoid) stroke aged $\geq 18$ years old who were admitted between 1 January 2010-31 December 2014 were included for analysis. Patients with transient ischaemic attack or unclear stroke cause were excluded. The International Classification of Diseases (ICD) diagnosis codes were used for case inclusion (Supplementary Tables 1 and 2) and exclusion (Supplementary Tables 3 and 4). Patients with first-ever stroke did not have any ICD codes for stroke identified in the NHG CDMS before 2010. In addition, we excluded patients who were not Singapore citizens or permanent residents, had hospital transfers, with unknown discharge status or with missing medication data.

\section{Drugs of Interest}

Drugs of interest included thrombolytic agents during hospitalisation, antithrombotics (antiplatelets, oral and parenteral anticoagulants) within 3 days of hospital admission, as well as oral antithrombotics (antiplatelets and anticoagulants) and statins at discharge (Supplementary Table 5). Medications prescribed (ever used) during hospitalisation or at discharge were identified based on the dispensed status and date of record relative to the discharge date of each patient.

\section{Demographic and Clinical Characteristics of Interest}

Apart from drug use, demographic and clinical data collected include sex, age, ethnicity, year of admission (for first-ever stroke), cardiovascular comorbidities, intensive care unit admission and hospital length of stay (LOS). These were decided based on variables commonly reported in existing literature, as well as data availability in the NHG CDMS.

\section{Statistical Analysis}

Categorical variables were presented as $\mathrm{n}(\%)$, while non-normally distributed continuous variables as median (interquartile range, IQR). In-hospital drug utilisation was analysed in the whole study cohort. Drug utilisation analyses of medications prescribed at discharge were conducted in a subcohort of patients discharged alive from non-rehabilitation departments. Patients discharged from rehabilitation departments were excluded, as some may have been transferred directly to inpatient rehabilitation wards within the same hospital or to affiliated community hospitals, hence resulting in missing drug records at discharge from acute care.

Association between drug utilisation and admission year were examined using the Cochran-Armitage test for trend and multivariable logistic regression adjusted for baseline characteristics including sex, age, ethnicity, cardiovascular comorbidities and hospital ward class (proxy for socioeconomic status). Patients admitted into Class $\mathrm{A}$ and Class B1 wards were considered private patients (receiving no to little government subsidy), whereas those in Class B2 and Class C wards were considered subsidised patients (receiving higher levels of government subsidy). ${ }^{13}$ ICD diagnosis codes and prescription of medications (e.g. statins, antidiabetic drugs) were used to determine comorbid conditions.

Patient characteristics associated with drug utilisation were also explored using multivariable logistic regression, adjusting for admission year to control for the effect of temporal changes in drug utilisation. Intensive care unit (ICU) admission and hospital LOS were used as proxies for stroke severity. Univariable analyses were performed to identify variables based on $P<0.10$. Selected variables were subsequently included in multivariable analyses and dropped via backward elimination if they did not achieve statistical significance of $P<0.05$.

Adjusted odds ratios (aORs) and corresponding 95\% confidence intervals (CIs) were reported. Independent variables were dropped if collinearity was detected during regression. All statistical analyses were conducted using Stata 13.0 (StataCorp LP, College Station, Texas, United States [US]).

\section{Results}

\section{Characteristics and Outcomes of Study Population}

Of the 4935 first-ever stroke patients in the whole study cohort, $69.1 \%$ had ischaemic stroke and $30.9 \%$ had haemorrhagic stroke (Fig. 1). The subcohort comprised 


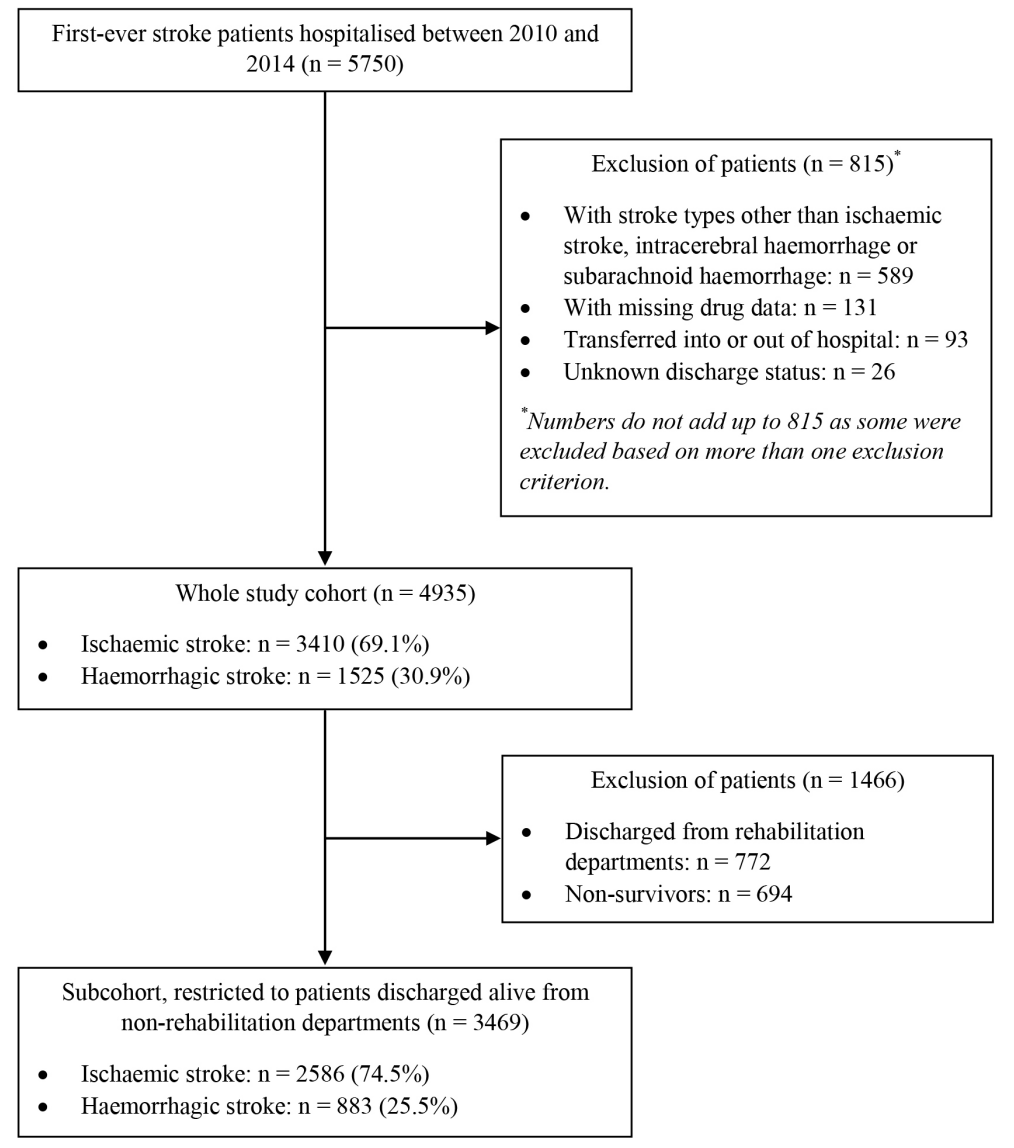

Fig. 1. Flow diagram of patient inclusion and exclusion.

3469 patients, of whom $74.5 \%$ had ischaemic stroke and $25.5 \%$ had haemorrhagic stroke.

The majority of ischaemic stroke patients were male, aged $\geq 65$ years old, of Chinese ethnicity, admitted to subsidised wards, and with hypertension and hyperlipidaemia (Table 1). Inpatient all-cause mortality averaged $10.1 \%$ over the 5 -year period. ICU admission and median hospital LOS were $14.9 \%$ and 9 (IQR: 4-21) days in the whole cohort, and $9.6 \%$ and 8 (IQR: 4-17) days in the subcohort, respectively.

Unlike ischaemic stroke patients, the majority of haemorrhagic stroke patients were aged $<65$ years old, with inpatient all-cause mortality averaging $22.8 \%$ (Table 1). ICU admission and median hospital LOS were $62.4 \%$ and 15 (IQR: 6-35) days in the whole cohort, and 49.7\% and 16 (IQR: 8-31) days in the subcohort, respectively.

\section{Temporal Trends of Drug Utilisation in Ischaemic Stroke}

An increasing trend in the combined use of all 3 guideline medications (in-hospital thrombolytic therapy, as well as antithrombotics and statins at discharge) was observed $(P<0.001)$ (Fig. 2A and Table 2). Compared with 2010, there was a 1.9-fold increase (95\% CI: 1.23-2.89) in 2014.
This increasing trend was similarly observed for use of thrombolytic agents $(P<0.001)$ (Fig. 2B and Table 2). Conversely, prescription of early antithrombotics (within 3 days of admission) was lower in 2014 (aOR $=0.71,95 \%$ CI: 0.55-0.91) compared with 2010.

Most patients received oral antithrombotics $(83.7 \%)$ at discharge, predominantly antiplatelets (73.9\%) (Fig. 2C and Table 2). There was an increasing trend in the prescription of oral antithrombotics $(P=0.002)$. Compared with 2010 , there was a 1.3-fold (95\% CI: $1.01-1.80)$ and 1.6-fold ( $95 \%$ CI: 1.17-2.12) increase in use of antiplatelets in 2013 and 2014 , respectively. Use of oral anticoagulants showed an increasing trend $(P=0.009)$, particularly for AF patients in $2014(\mathrm{aOR}=2.54,95 \% \mathrm{CI}: 1.44-4.46)$ compared with 2010. Oral anticoagulation use in non-AF patients was low, averaging $5.4 \%$.

Aspirin and clopidogrel were the most prescribed antiplatelets at discharge (Fig. 3A). Use of aspirin remained relatively stable from $2010-2014(P=0.510)$, while prescription of clopidogrel and aspirin-clopidogrel combination increased $(P<0.001)$ (Figs. 3A, 3B and Table 2). Combined aspirin-clopidogrel use in 2013 and 2014 
Table 1. Characteristics and Outcomes of Study Population, Stratified By Stroke Type

\begin{tabular}{|c|c|c|c|c|}
\hline & \multicolumn{2}{|c|}{ Ischaemic Stroke } & \multicolumn{2}{|c|}{ Haemorrhagic Stroke ${ }^{*}$} \\
\hline & $\begin{array}{c}\text { Cohort } \\
(n=3410)\end{array}$ & $\begin{array}{l}\text { Subcohort }^{\dagger} \\
(n=2586)\end{array}$ & $\begin{array}{c}\text { Cohort } \\
(n=1525)\end{array}$ & $\begin{array}{l}\text { Subcohort }^{\dagger} \\
(\mathrm{n}=\mathbf{8 8 3})\end{array}$ \\
\hline \multicolumn{5}{|l|}{ Characteristic } \\
\hline Male, n (\%) & $1951(57.2)$ & $1490(57.6)$ & $810(53.1)$ & 447 (50.6) \\
\hline Median age (IQR) & $69(59-79)$ & $69(59-79)$ & $61(52-72)$ & $61(52-72)$ \\
\hline \multicolumn{5}{|l|}{ Age group, n (\%) } \\
\hline $18-64$ & $1350(39.6)$ & $1039(40.2)$ & $902(59.1)$ & $517(58.6)$ \\
\hline $65-74$ & $828(24.3)$ & $598(23.1)$ & $330(21.6)$ & $199(22.5)$ \\
\hline $75-84$ & $824(24.2)$ & $633(24.5)$ & $209(13.7)$ & $123(13.9)$ \\
\hline$\geq 85$ & $408(12.0)$ & $316(12.2)$ & $84(5.5)$ & $44(5.0)$ \\
\hline \multicolumn{5}{|l|}{ Ethnic group, n (\%) } \\
\hline Chinese & $2614(76.7)$ & $1949(75.4)$ & $1219(79.9)$ & $692(78.4)$ \\
\hline Malay & $417(12.2)$ & $327(12.6)$ & $179(11.7)$ & $110(12.5)$ \\
\hline Indian & $207(6.1)$ & $164(6.3)$ & $59(3.9)$ & $38(4.3)$ \\
\hline Others & $172(5.0)$ & $146(5.6)$ & $68(4.5)$ & $43(4.9)$ \\
\hline \multicolumn{5}{|l|}{ Hospital ward class, $\mathrm{n}(\%)^{\ddagger}$} \\
\hline Private (Class A and Class B1) & $124(3.6)$ & $104(4.0)$ & $59(3.9)$ & $43(4.9)$ \\
\hline Subsidised (Class B2 and Class C) & $3286(96.4)$ & $2482(96.0)$ & $1466(96.1)$ & $840(95.1)$ \\
\hline \multicolumn{5}{|l|}{ Year of admission, $\mathrm{n}(\%)$} \\
\hline 2010 & $824(24.2)$ & $638(24.7)$ & $381(25.0)$ & $209(23.7)$ \\
\hline 2011 & $659(19.3)$ & $489(18.9)$ & $275(18.0)$ & $159(18.0)$ \\
\hline 2012 & $686(20.1)$ & $516(20.0)$ & $296(19.4)$ & $173(19.6)$ \\
\hline 2013 & $638(18.7)$ & $481(18.6)$ & $276(18.1)$ & $161(18.2)$ \\
\hline 2014 & $603(17.7)$ & $462(17.9)$ & $297(19.5)$ & $181(20.5)$ \\
\hline Hypertension & $2600(76.2)$ & $1950(75.4)$ & $1080(70.8)$ & $644(72.9)$ \\
\hline Hyperlipidaemia & 3237 (94.9) & $2484(96.1)$ & $852(55.9)$ & $525(59.5)$ \\
\hline Diabetes mellitus & $1571(46.1)$ & $1155(44.7)$ & $362(23.7)$ & $233(26.4)$ \\
\hline Atrial fibrillation & $873(25.6)$ & $608(23.5)$ & $104(6.8)$ & $63(7.1)$ \\
\hline Coronary heart disease & $815(23.9)$ & $593(22.9)$ & $176(11.5)$ & $100(11.3)$ \\
\hline Heart failure & $411(12.1)$ & $295(11.4)$ & $76(5.0)$ & $40(4.5)$ \\
\hline Chronic kidney disease & $1050(30.8)$ & $790(30.5)$ & $282(18.5)$ & $167(18.9)$ \\
\hline \multicolumn{5}{|c|}{ Number of cardiovascular comorbidities, $\mathrm{n}(\%)^{\S}$} \\
\hline$\leq 3$ & $2146(62.9)$ & $1662(64.3)$ & $1286(84.3)$ & $733(83.0)$ \\
\hline$>3$ & $1264(37.1)$ & $924(35.7)$ & $239(15.7)$ & $150(17.0)$ \\
\hline \multicolumn{5}{|l|}{ Outcome } \\
\hline Inpatient all-cause mortality, n (\%) & $346(10.1)$ & $0(0.0)$ & $348(22.8)$ & $0(0.0)$ \\
\hline Admitted to ICU, n (\%) & $508(14.9)$ & $248(9.6)$ & $951(62.4)$ & $439(49.7)$ \\
\hline Median ICU LOS (days) (IQR) & $2(1-5)$ & $2(1-5)$ & $3(2-7)$ & $3(2-7)$ \\
\hline Median hospital LOS (days) (IQR) & $9(4-21)$ & $8(4-17)$ & $15(6-35)$ & $16(8-31)$ \\
\hline Hospital LOS > 8 days, n (\%) & $1786(52.4)$ & $1193(46.1)$ & $1014(66.5)$ & $651(73.7)$ \\
\hline Hospital LOS >16 days, n (\%) & $1114(32.7)$ & $670(25.9)$ & $723(47.4)$ & $430(48.7)$ \\
\hline
\end{tabular}

ICU: Intensive care unit; IQR: Interquartile range; LOS: Length of stay

"Includes intracerebral haemorrhage and subarachnoid haemorrhage.

${ }^{\dagger}$ Restricted to patients discharged alive from non-rehabilitation departments.

*Patients admitted into class A and class B1 wards are considered private patients; those in class B2 and class C wards are considered subsidised patients (Source: Ministry of Health, Singapore. Hospital Services. 2018. Available at: https://www.moh.gov.sg/our-healthcare-system/healthcare-services-andfacilities/hospital-services. Accessed on 17 June 2019).

${ }^{\S}$ Based on cardiovascular comorbidities, namely hypertension, hyperlipidaemia, diabetes mellitus, atrial fibrillation, coronary heart disease, heart failure and chronic kidney disease. 
A)

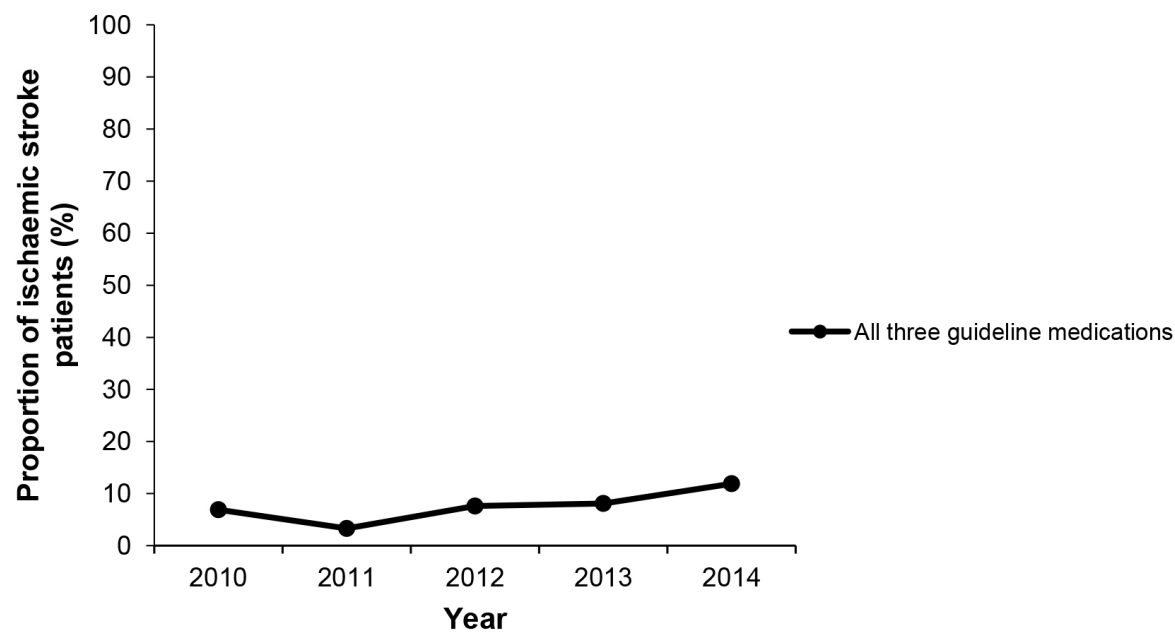

B)

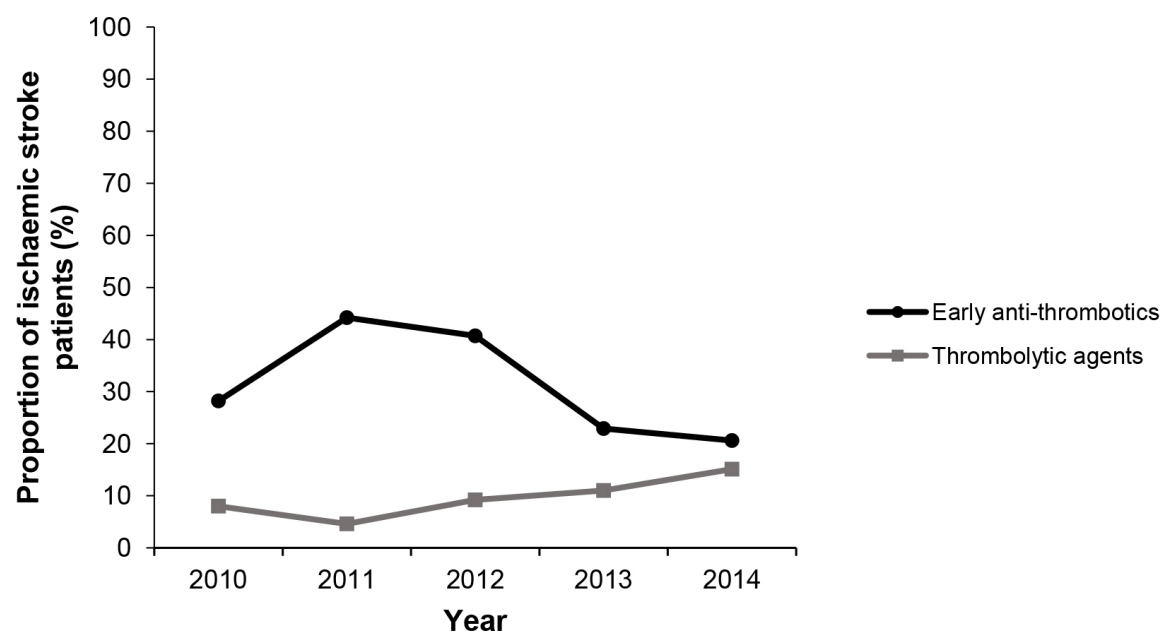

C)

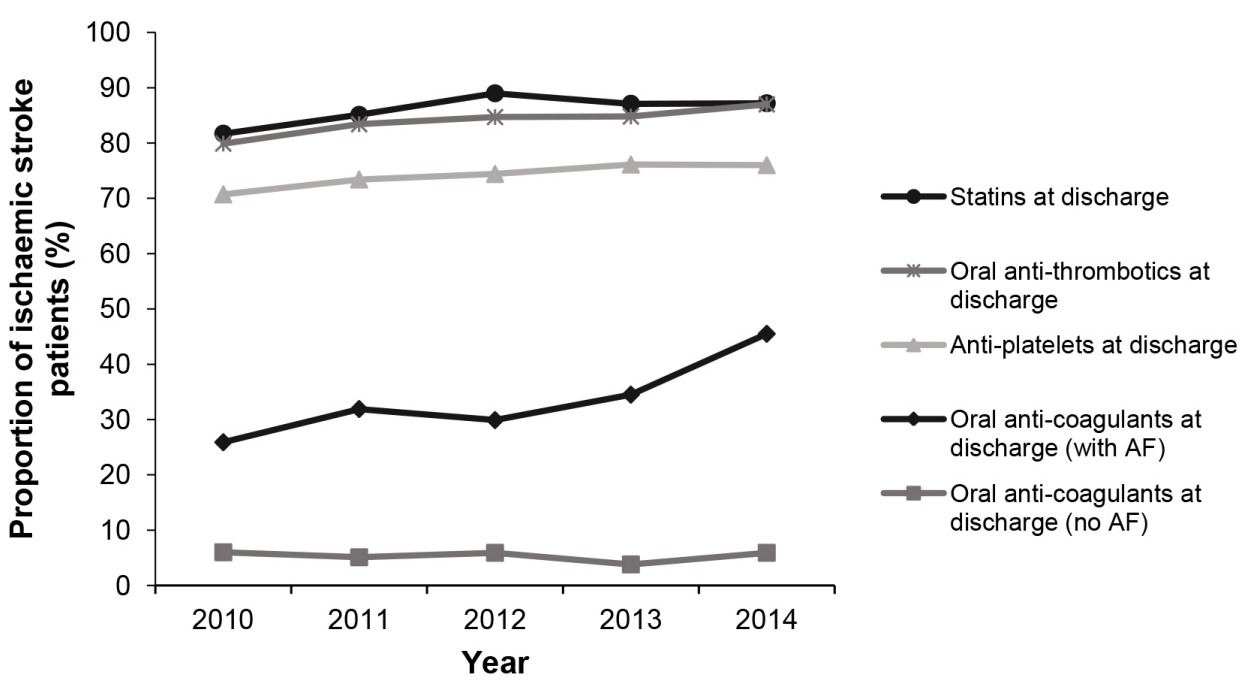


D)

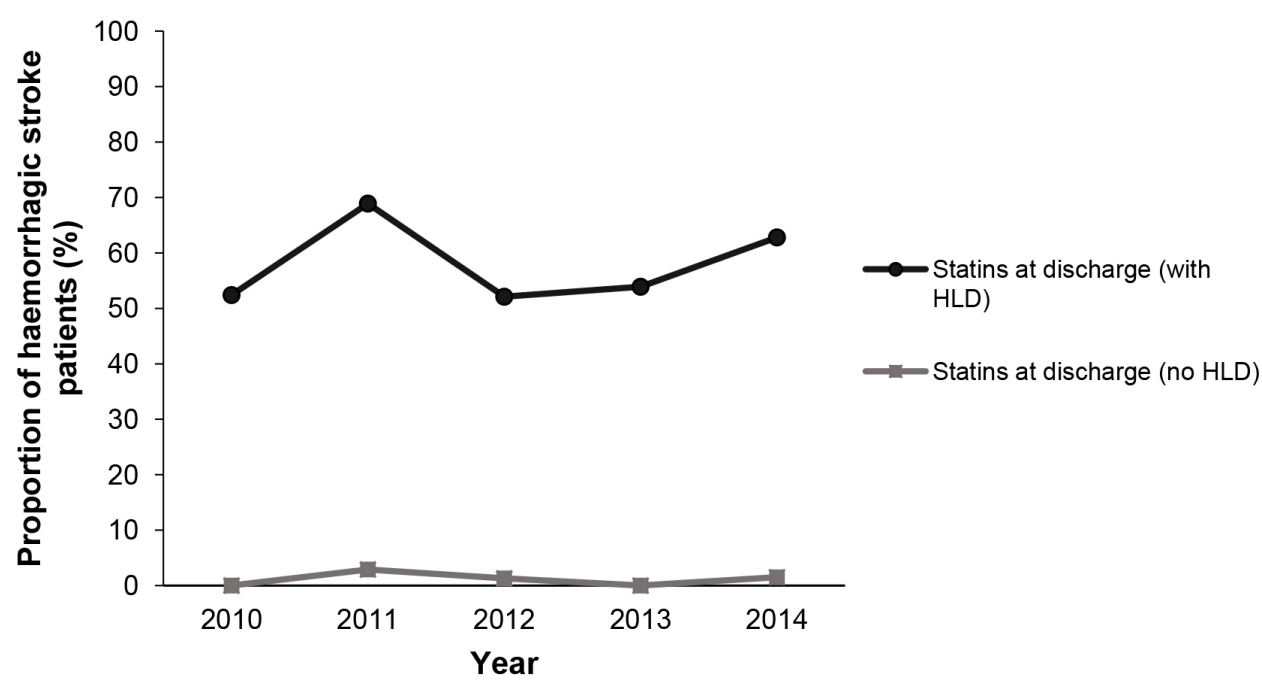

Fig. 2. Drug utilisation trends. A: Use of all 3 guideline medications (in-hospital thrombolytic agents, as well as antithrombotics and statins at discharge) in ischaemic stroke. B: In-hospital drug use in ischaemic stroke. C: Drugs prescribed at discharge in ischaemic stroke. D: Statins prescribed at discharge in haemorrhagic stroke. AF: Atrial fibrillation, HLD: Hyperlipidaemia

were 3.0-fold (95\% CI: $1.66-5.28)$ and 5.3-fold (95\% CI: $3.08-9.16)$ of 2010 , respectively. Specifically, prescription of this dual antiplatelet combination after July 2013 was 2.9-fold (95\% CI: 2.06-4.04) of the period before. Use of dipyridamole and aspirin-dipyridamole combination showed decreasing trends $(P<0.001)$, while ticlopidine and clopidogrel-dipyridamole combination were almost negligible (Figs. 3A, 3B and Table 2).

Warfarin was the most prescribed oral anticoagulant at discharge (Fig. 3C), averaging 10.2\% $(P=0.738)$ (Table 2 ). Use of the direct oral anticoagulants (DOACs), namely dabigatran, rivaroxaban and apixaban started in 2011, 2013 and 2014, respectively. In 2014, 10.8\%, 2.6\%, 2.4\% and $0.6 \%$ of patients were prescribed warfarin, apixaban, rivaroxaban and dabigatran, respectively.

There was an increasing trend in the prescription of statins at discharge $(P=0.003)$ (Fig. $2 \mathrm{C}$ and Table 2$)$. Simvastatin and atorvastatin were the most prescribed statins, with use averaging $68.4 \%$ and $19.8 \%$, respectively (Fig. 4 and Table 2). Simvastatin utilisation declined from $76.6 \%$ in 2010 to $37.4 \%$ in $2014(P<0.001)$, with prescription lower in 2013 $(\mathrm{aOR}=0.60,95 \%$ CI: $0.45-0.80)$ and $2014(\mathrm{aOR}=0.17$, $95 \%$ CI: 0.12-0.22), compared with 2010. Conversely, an increasing trend in atorvastatin prescription was observed from $4.2 \%$ in 2010 to $51.1 \%$ in $2014(P<0.001)$. Utilisation of lovastatin and rosuvastatin were comparatively much lower, averaging $2.0 \%$ and $0.7 \%$, respectively.

\section{Predictors of Drug Utilisation in Ischaemic Stroke}

Patients $<85$ years old, of Malay ethnicity, with hyperlipidaemia or AF, but without chronic kidney disease (CKD), were more likely to receive all 3 guideline medications (Table 3 ). Patients $<75$ years old, with AF or coronary heart disease (CHD), but without CKD, were more likely to be administered thrombolytic agents. Patients $<65$ years old, of Indian ethnicity, with hyperlipidaemia, but without hypertension or AF, were more likely to be prescribed early antithrombotics. Patients $<75$ years old, with hyperlipidaemia, without $\mathrm{AF}$, without ICU admission or with shorter hospital LOS ( $\leq 8$ days), were more likely to receive antiplatelets at discharge. Patients $<65$ years old, with $\mathrm{AF}$ or $\mathrm{CHD}$, but without diabetes mellitus, were more likely to be prescribed oral anticoagulants at discharge. When restricted to only AF patients, age $<75$ years old, no diabetes mellitus and shorter hospital LOS ( $\leq 8$ days) were predictors for oral anticoagulation use. Patients $<85$ years old, with hyperlipidaemia, without ICU admission or with shorter hospital LOS ( $\leq 8$ days) were more likely to receive statins at discharge.

\section{Temporal Trends of Statin Utilisation in Haemorrhagic Stroke}

Prescription of statins at discharge averaged 34.8\% (Fig. 2D and Table 2). A total of $57.7 \%$ of patients with hyperlipidaemia received statins.

\section{Predictors of Statin Utilisation in Haemorrhagic Stroke}

Patients with hyperlipidaemia, CHD or without ICU admission, were more likely to be prescribed statin therapy at discharge (Table 3). When restricted to those with hyperlipidaemia, CHD and without ICU admission remained as significant predictors. 


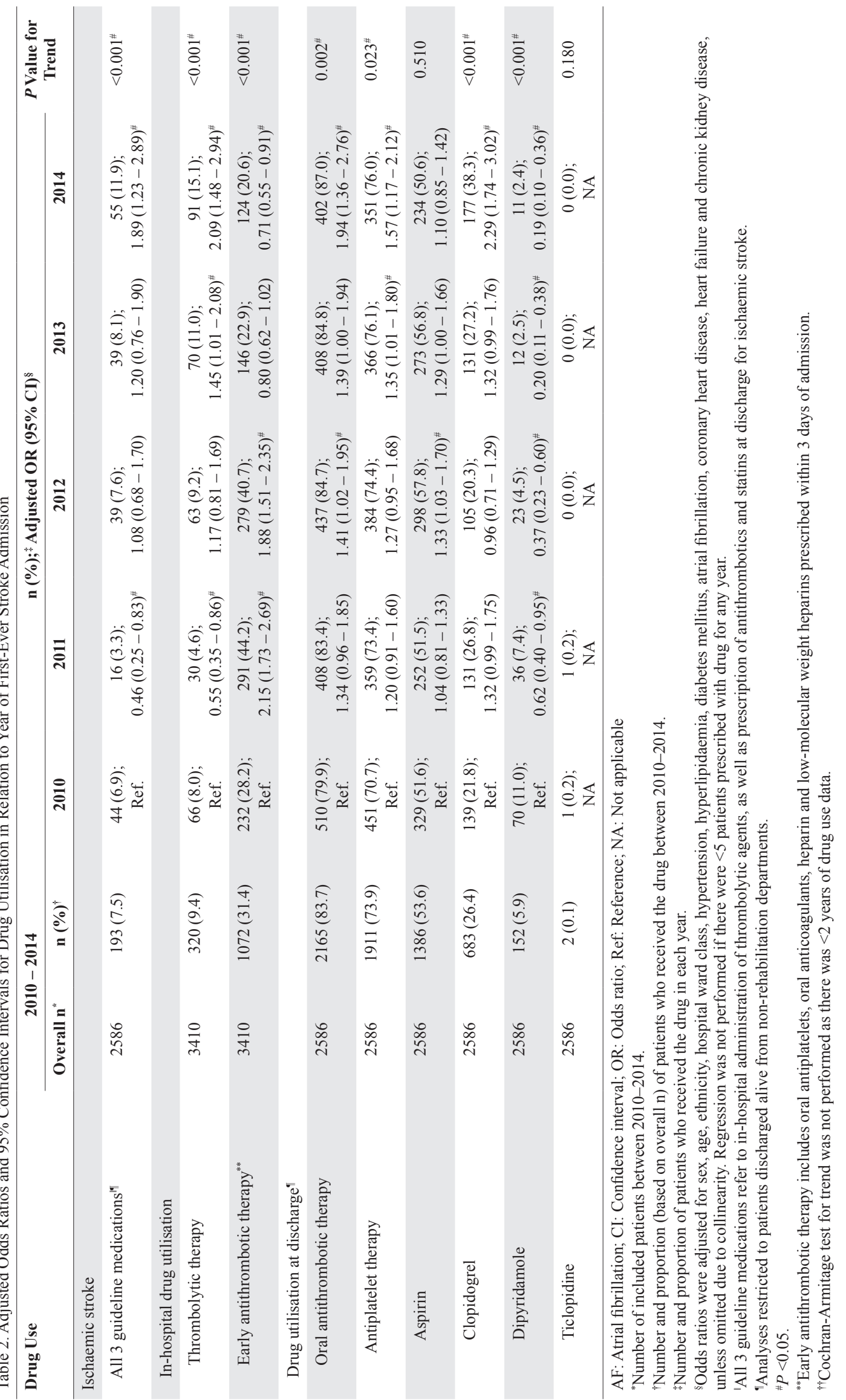




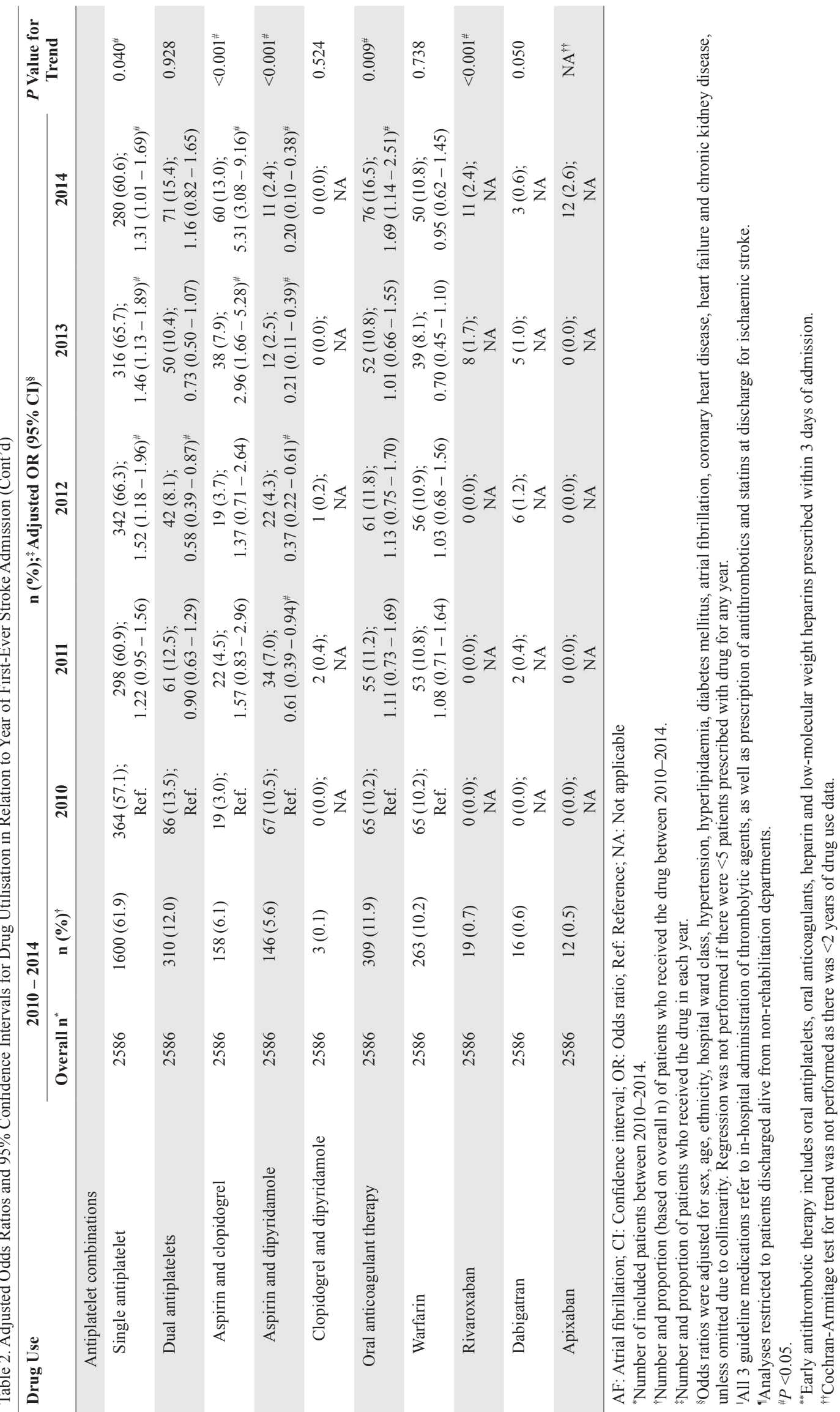




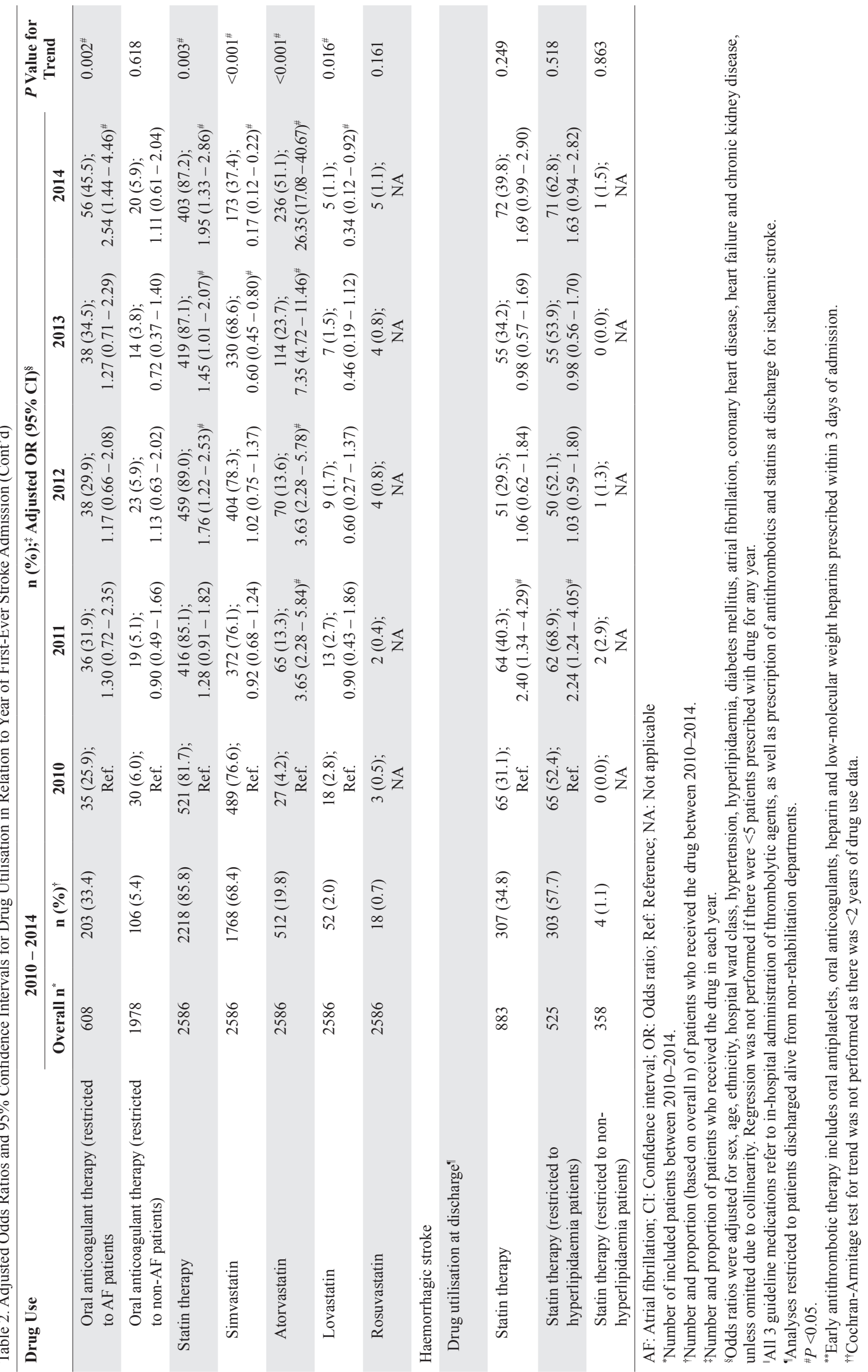


A)

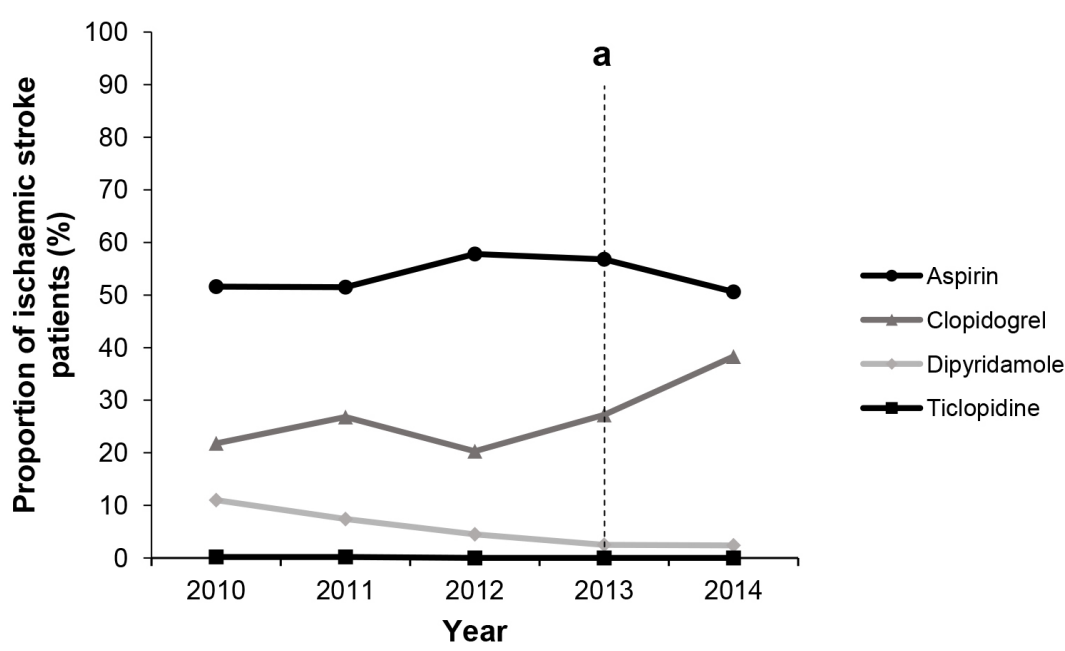

B)
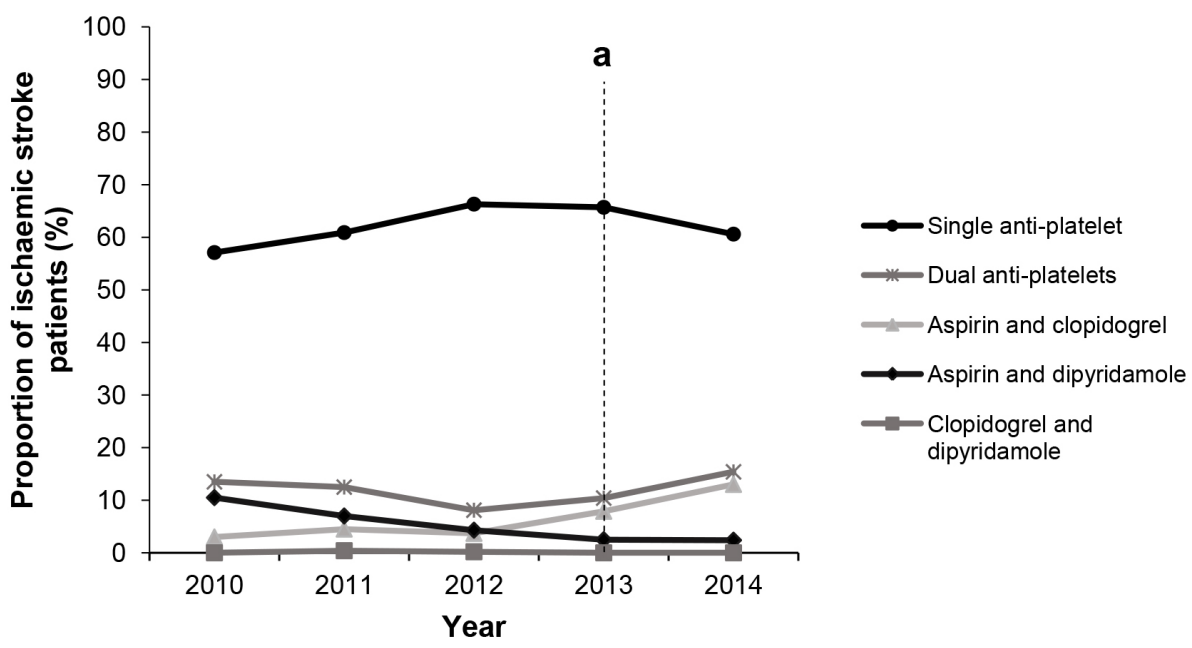

C)

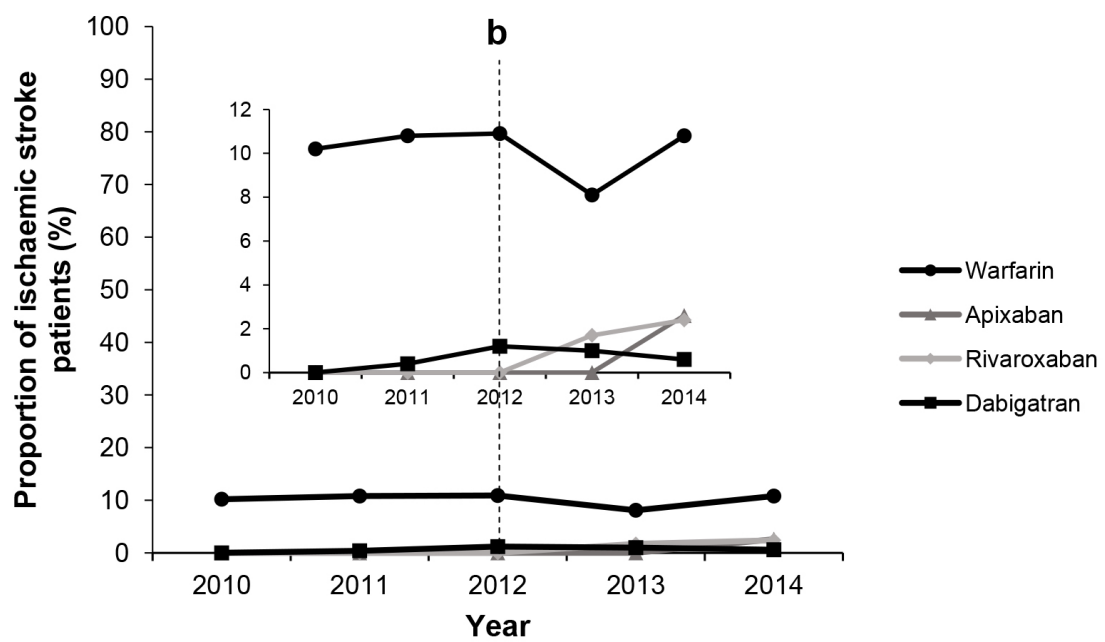

Fig. 3. Antithrombotic utilisation trends at discharge in ischaemic stroke. A: Specific antiplatelets. B: Selected antiplatelet combinations. C: Specific anticoagulants. The inset in C is presented on a different scale. Line "a" in graphs A and B points to the year in which results from the Clopidogrel in High-Risk Patients with Acute Non-disabling Cerebrovascular Events (CHANCE) trial was published (i.e. July 2013), showing that the early use of aspirin and clopidogrel combination was superior to aspirin alone for reducing risk of stroke (Wang Y, Wang Y, Zhao X, Liu L, Wang D, Wang C, et al. Clopidogrel with aspirin in acute minor stroke or transient ischemic attack. N Engl J Med 2013;369:11-9). Line "b" in graph C points to the year in which dabigatran, apixaban and rivaroxaban were added into the American Heart Association/ American Stroke Association guidelines for prevention of stroke in patients with non-valvular atrial fibrillation (i.e. 2012) (Furie KL, Goldstein LB, Albers GW, Khatri P, Neyens R, Turakhia MP, et al. Oral antithrombotic agents for the prevention of stroke in nonvalvular atrial fibrillation: a science advisory for healthcare professionals from the American Heart Association/American Stroke Association. Stroke 2012;43:3442-53). 
Table 3. Predictors of Drug Utilisation Using Multivariable Logistic Regression

\begin{tabular}{|c|c|c|c|c|}
\hline Drug Use & Overall $\mathbf{n}^{*}$ & $\mathbf{n}(\%)^{\dagger}$ & Predictor $^{\star}$ & Adjusted OR $(95 \% \text { CI })^{\S}$ \\
\hline \multicolumn{5}{|l|}{ Ischaemic stroke } \\
\hline \multirow[t]{11}{*}{ All 3 guideline medications ${ }^{1}$} & 2586 & $193(7.5)$ & Age group & \\
\hline & & & $18-64$ & Ref. \\
\hline & & & $65-74$ & $0.87(0.59-1.27)$ \\
\hline & & & $75-84$ & $0.67(0.44-1.01)$ \\
\hline & & & Ethnic group & \\
\hline & & & Chinese & Ref. \\
\hline & & & Malay & $1.79(1.21-2.64)$ \\
\hline & & & Indian & $1.19(0.64-2.24)$ \\
\hline & & & Others & $1.10(0.57-2.12)$ \\
\hline & & & With atrial fibrillation & $2.54(1.82-3.57)$ \\
\hline & & & With chronic kidney disease & $0.60(0.41-0.86)$ \\
\hline \multirow[t]{8}{*}{ Administration of thrombolytic agent } & 3410 & $320(9.4)$ & Age group & \\
\hline & & & $18-64$ & Ref. \\
\hline & & & $65-74$ & $0.93(0.70-1.25)$ \\
\hline & & & $75-84$ & $0.67(0.49-0.93)$ \\
\hline & & & $\geq 85$ & $0.38(0.23-0.63)$ \\
\hline & & & With atrial fibrillation & $2.19(1.69-2.84)$ \\
\hline & & & With coronary heart disease & $1.47(1.12-1.94)$ \\
\hline & & & With chronic kidney disease & $0.61(0.45-0.81)$ \\
\hline \multirow{12}{*}{$\begin{array}{l}\text { Early antithrombotic therapy (within } 3 \\
\text { days of admission) }\end{array}$} & 3410 & $1072(31.4)$ & Age group & \\
\hline & & & $65-74$ & $0.81(0.67-0.98)$ \\
\hline & & & $75-84$ & $0.66(0.54-0.81)$ \\
\hline & & & $\geq 85$ & $0.49(0.37-0.65)$ \\
\hline & & & Ethnic group & \\
\hline & & & Chinese & Ref. \\
\hline & & & Malay & $1.22(0.97-1.53)$ \\
\hline & & & Indian & $1.40(1.04-1.90)$ \\
\hline & & & Others & $1.28(0.91-1.79)$ \\
\hline & & & With hypertension & $0.71(0.59-0.84)$ \\
\hline & & & With hyperlipidaemia & $2.56(1.65-3.97)$ \\
\hline & & & With atrial fibrillation & $0.76(0.63-0.92)$ \\
\hline \multirow[t]{5}{*}{ Antiplatelet therapy at discharge } & 2586 & $1911(73.9)$ & Age group & \\
\hline & & & $18-64$ & Ref. \\
\hline & & & $65-74$ & $0.87(0.67-1.13)$ \\
\hline & & & $75-84$ & $0.77(0.59-0.99)$ \\
\hline & & & $\geq 85$ & $0.65(0.47-0.89)$ \\
\hline
\end{tabular}

CI: Confidence interval; ICU: Intensive care unit; OR: Odds ratio; Ref: reference

"Number of patients included in model.

Number and proportion (based on overall $\mathrm{n}$ ) of patients who received the drug.

Unless otherwise stated, reference group comprised of patients who did not have the comorbidity or were not admitted to ICU.

\$Odds ratios were adjusted for all covariates listed in the table, as well as year of admission to control for the effect of temporal changes in drug utilisation.

'All 3 guideline medications refer to in-hospital administration of thrombolytic agents, as well as prescription of antithrombotics and statins at discharge for ischaemic stroke. 
Table 3. Predictors of Drug Utilisation Using Multivariable Logistic Regression (Cont'd)

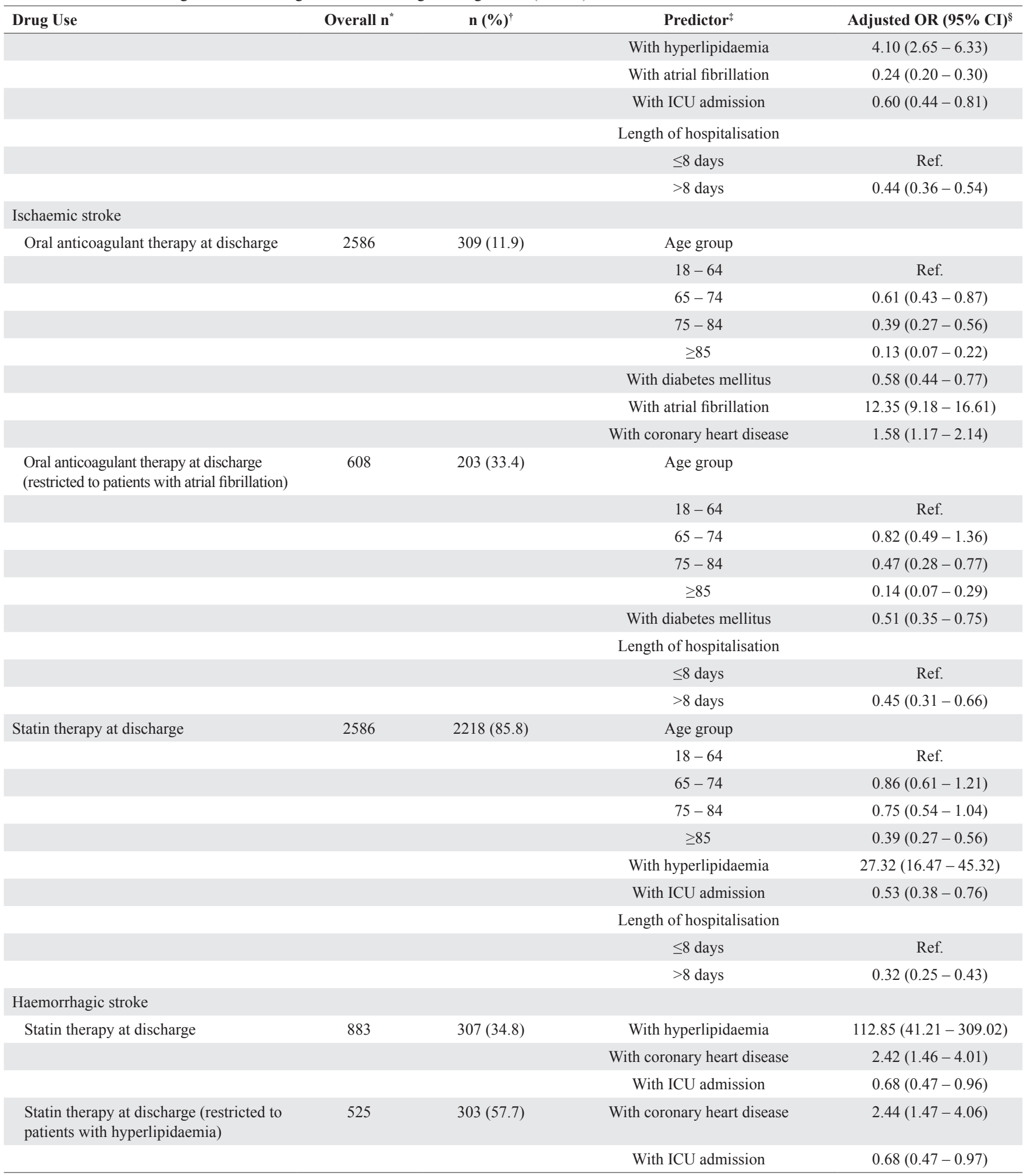

CI: Confidence interval; ICU: Intensive care unit; OR: Odds ratio; Ref: reference

"Number of patients included in model.

${ }^{\dagger}$ Number and proportion (based on overall $\mathrm{n}$ ) of patients who received the drug.

Unless otherwise stated, reference group comprised of patients who did not have the comorbidity or were not admitted to ICU.

${ }^{\S}$ Odds ratios were adjusted for all covariates listed in the table, as well as year of admission to control for the effect of temporal changes in drug utilisation.

'All 3 guideline medications refer to in-hospital administration of thrombolytic agents, as well as prescription of antithrombotics and statins at discharge

for ischaemic stroke. 


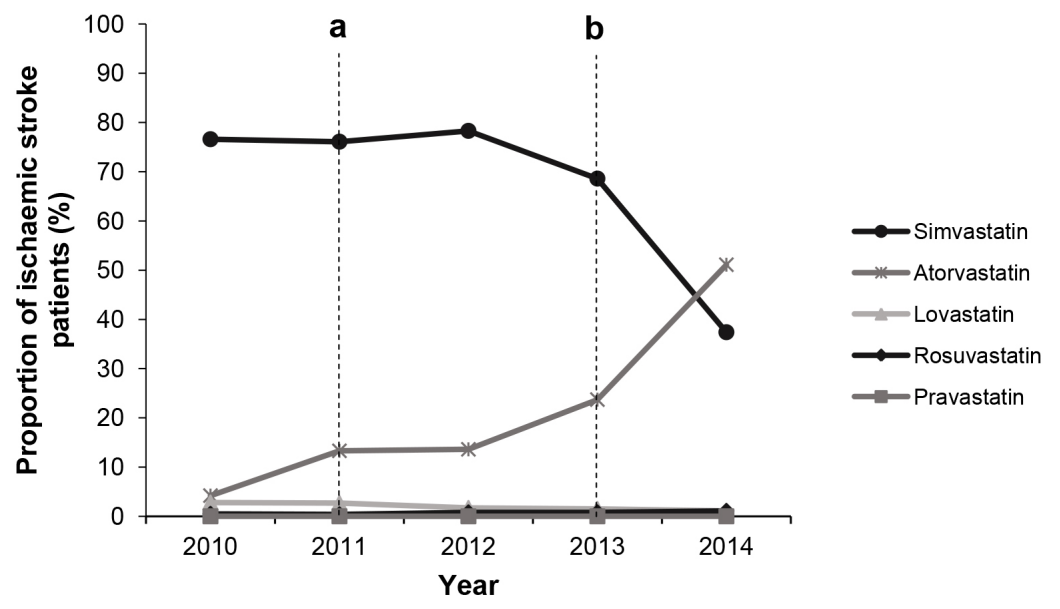

Fig. 4. Trends in specific statin prescribed at discharge for ischaemic stroke patients. Line "a" indicates the year in which the treatment goal for low-density lipoprotein-C was modified from $<2.6 \mathrm{mmol} / \mathrm{L}$ to a reduction of at least $50 \%$ or $<1.8 \mathrm{mmol} / \mathrm{L}$ in the American Heart Association/American Stroke Association guidelines (i.e. 2011) (Adams RJ, Albers G, Alberts MJ, Benavente O, Furie K, Goldstein LB, et al. Update to the AHA/ASA recommendations for the prevention of stroke in patients with stroke and transient ischemic attack. Stroke 2008;39:1647-52; Furie KL, Kasner SE, Adams RJ, Albers GW, Bush RL, Fagan SC, et al. Guidelines for the prevention of stroke in patients with stroke or transient ischemic attack: a guideline for healthcare professionals from the American Heart Association/American Stroke Association. Stroke 2011;42:227-76). Patent for atorvastatin (Lipitor ${ }^{\mathbb{R}}$ ) also expired in 2011 (Loch A, Bewersdorf JP, Kofink D, Ismail D, Abidin IZ, Veriah RS. Generic atorvastatin is as effective as the brand-name drug (LIPITOR ${ }^{\mathbb{R}}$ ) in lowering cholesterol levels: a crosssectional retrospective cohort study. BMC Res Notes 2017;10:291). Line "b" indicates the year in which guidelines from the American College of Cardiology/ American Heart Association were published (i.e. 2013) on the treatment of blood cholesterol to reduce atherosclerotic cardiovascular risk in adults (including stroke), encouraging use of high-intensity statin therapy (Stone NJ, Robinson JG, Lichtenstein AH, Bairey Merz CN, Blum CB, Eckel RH, et al. 2013 ACC/ AHA guideline on the treatment of blood cholesterol to reduce atherosclerotic cardiovascular risk in adults: a report of the American College of Cardiology/ American Heart Association Task Force on Practice Guidelines. Circulation 2014;129:S1-45).

\section{Discussion}

This study examined temporal trends and patient characteristics associated with drug utilisation among firstever stroke patients admitted to 2 Singapore tertiary hospitals from 2010-2014. The increased use of all 3 guideline medications in ischaemic stroke was driven by increasing in-hospital use of thrombolytic agents, prescription of oral antithrombotics and statins at discharge. Younger patients, of Malay ethnicity, with hyperlipidaemia or AF but without CKD, were more likely to receive all 3 guideline medications. Among the antithrombotics, clopidogrel and combined aspirin-clopidogrel use had increased. For statins, the increase in atorvastatin prescription was accompanied by decreasing use of simvastatin. In haemorrhagic stroke, prescription of statins at discharge was expectedly lower than in ischaemic stroke.

Alteplase, a recombinant tissue plasminogen activator (rtPA), has been approved for treatment of acute ischaemic stroke since 1996.,14 As the benefit of thrombolysis diminishes over time, it was initially recommended within 3 hours of stroke-onset. ${ }^{15}$ Delayed hospital arrival could reduce the number of eligible patients for thrombolysis. ${ }^{16}$ The European Cooperative Acute Stroke Study (ECASS)-3 (published in 2008) provided evidence that intravenous rtPA could be safely administered to selected patients 3-4.5 hours after stroke. ${ }^{17}$ An advisory was subsequently published by AHA/ASA, expanding the time window for thrombolytic therapy in 2009. ${ }^{18}$ The observed increased utilisation of rtPA in our study was encouraging and could be attributed to both national and local efforts promoting its use. Guidelines from the Ministry of Health, Singapore were published in 2013, recommending treatment within 4.5 hours poststroke in centres with appropriate facilities and expertise. ${ }^{19}$ Reorganisation of hospital acute stroke services, implementation of drug protocols and identification of ischaemic stroke patients quickly in the emergency department could have resulted in more patients meeting the therapeutic time window.

The cumulative risk of stroke recurrence is high and antiplatelets are the cornerstone of secondary ischaemic stroke prevention. ${ }^{20}$ Prior to 2014, the AHA/ASA guidelines recommended aspirin, aspirin-dipyridamole combination and clopidogrel as options for initial therapy, while use of aspirin-clopidogrel combination was discouraged due to increased risk of haemorrhage. ${ }^{21}$ In our study, we observed increased prescription of aspirin-clopidogrel combination in 2013 and 2014 over 2010, coinciding with publication of the Clopidogrel in High-Risk Patients with Acute Nondisabling Cerebrovascular Events (CHANCE) trial in July 2013. The CHANCE trial included Chinese patients with minor ischaemic stroke or transient ischaemic attack, and showed that treatment with aspirin-clopidogrel combination for 21 days, followed by clopidogrel alone for a total of 90 days, was superior to aspirin alone in reducing stroke 
recurrence. ${ }^{22}$ While the AHA/ASA updated the guidelines only in the subsequent year to incorporate findings from the trial, ${ }^{1}$ prescription of the drug combination had increased ahead of guideline changes. Increasing use of clopidogrel could also be attributed to expiration of its patent in 2012.23

Anticoagulants have better efficacy than antiplatelets for prevention of cardioembolic stroke due to $\mathrm{AF}^{24,25}$ Although we observed an increasing trend for prescription of oral anticoagulants for AF patients, the average use of 33.4\% was lower than other Western countries such as Australia $(57.4 \%)^{26}$ and the US (91.1\%). ${ }^{27}$ Concerns over bleeding complications including haemorrhagic conversion may explain the lower utilisation of oral anticoagulants in our ischaemic stroke population, as some evidence has suggested that risk of bleeding is higher for Asians than non-Asians. ${ }^{28,29}$ For many years, warfarin was the only oral anticoagulant available. Other approved DOACs were subsequently added to the AHA/ASA guidelines in $2012 .{ }^{30}$ These newer agents have several advantages over warfarin, including reduced risk of intracranial haemorrhage, need for monitoring and potential for drug-drug or drug-food interactions. ${ }^{31}$ However, higher costs of DOACs relative to warfarin could hinder utilisation in clinical practice. Between 2010-2014, warfarin was the predominant anticoagulant prescribed. With granting of government subsidies, and costs of DOACs to patients reduced, ${ }^{32}$ there were subsequent greater utilisation of DOACs. Despite apixaban being the latest DOAC to be approved, its use had overtaken rivaroxaban and dabigatran in 2014. Practical considerations may have favoured the prescribing of apixaban over other DOACs. Dabigatran capsules cannot be broken, making it unsuitable for patients on enteral tube feeding that requires crushing or dissolution of medications. ${ }^{33}$ Dabigatran also interacts with acid suppressants,$^{34}$ which may often be prescribed concomitantly with antithrombotics for gastric protection. ${ }^{35}$ While randomised trials had reported that DOACs were non-inferior to warfarin in reducing stroke risk, apixaban was the only DOAC associated with a significantly lower rate of major bleeding. ${ }^{36}$

In 2011, the treatment goal for low-density lipoprotein-C (LDL-C) was modified from $<2.6 \mathrm{mmol} / \mathrm{L}$ to a reduction of at least $50 \%$ or $<1.8 \mathrm{mmol} / \mathrm{L}$ in the AHA/ASA guidelines. ${ }^{21,37}$ Subsequently in 2013 and 2014, guidelines were revised to recommend statins to all patients with stroke secondary to atherosclerosis, encouraging use of high-intensity therapies which can potentially lower LDL-C by $\geq 50 \%{ }^{1,3}$ A torvastatin (40-80 mg/day) and rosuvastatin $(20-40 \mathrm{mg} /$ day $)$ are considered high-intensity therapies, while simvastatin, lovastatin and pravastatin are considered low- to moderateintensity therapies at their recommended doses. ${ }^{3}$ In our study, there was an increasing trend in prescription of atorvastatin, while the inverse was observed for simvastatin. Based on the guideline changes, ${ }^{1,3,21,37}$ prescription of higher potency statins is expected to rise. Although atorvastatin prescription had increased from $4.2 \%$ in 2010 to $51.1 \%$ in 2014 , utilisation of rosuvastatin remained low. This preferential prescription of atorvastatin could be explained by the coincidental patent expiration for atorvastatin $\left(\right.$ Lipitor $\left.^{\circledR}\right)$ in 2011 that allowed generics to enter the market. ${ }^{38}$ Conversely, the patent for rosuvastatin $\left(\right.$ Crestor $\left.^{\circledR}\right)$ remained in force during the study period. ${ }^{39}$ Future studies could examine change in rosuvastatin use, after its patent expiration in 2016. ${ }^{39}$ The reduced utilisation of simvastatin may also be due to safety alerts from the US Food and Drug Administration in 201140 and Health Sciences Authority of Singapore in $2012^{41}$ to avoid use of the highest approved dose of simvastatin $(80$ $\mathrm{mg}$ ) due to greater risk of myopathy, prompting physicians to switch to prescribing other statins.

Our results showed significant associations between ethnicity and drug utilisation in ischaemic stroke. Compared with Chinese, Malays were more likely to receive all 3 guideline medications, while Indians were more likely to receive early antithrombotics. Previous studies conducted in the US had also reported ethnicity to be a significant predictor for drug use in stroke. ${ }^{7,42-45}$ Access to specialised medical facilities, socioeconomic status, time to hospital arrival, stroke severity and drug contraindications, could differ by ethnicity and hence explain for the observed differences in drug utilisation. ${ }^{7,42-45}$ In addition, based on the General Household Survey 2015 in Singapore, Malay residents aged $\geq 65$ years old (69.8\%) were more likely to live with their children and less likely to live alone, compared with Chinese $(60.6 \%)$ and Indians $(60.8 \%){ }^{46}$ The higher level of caregiver support in the Malays could be another possible reason why they were more likely to receive all 3 guideline medications. A prospective study will be more suitable to evaluate how ethnicity and social factors influence drug utilisation, as such information on caregiver support and family structure are not routinely captured in the NHG CDMS.

In our study, ICU admission and longer hospital LOS reduced the likelihood for prescription of antiplatelets and statins at discharge. An earlier stroke study had reported that ICU admission was significantly associated with increased 30-day and 1-year mortality, while longer LOS increased death risk within 1 year. ${ }^{47}$ Patients who had ICU admission or longer LOS may have poorer prognosis after hospital discharge. Hence, these patients could be considered by physicians as less likely to benefit from use of secondary stroke preventive medications.

The study's limitations include the reliance of our findings on the completeness of data in the NHG CDMS. We were unable to perform more in-depth analyses as information on drug doses and duration were not available. Data on 
some variables which may influence drug utilisation such as education level, stroke severity, poststroke functional independence and cognition were also not captured. Physicians may consider these factors when prescribing drugs, as they impact the patient's ability to manage medications after hospital discharge. ${ }^{26}$ In addition, some surgical procedures, such as decompressive surgery of large infarcts, may delay early prescription of antithrombotics in ischaemic stroke; however, this information was not captured in NHG CDMS. In our study, while we used hospital ward class as a proxy for patients' socioeconomic status, this may not be an accurate reflection as ward class may be influenced by personal preferences, insurance coverage and employment benefits. Furthermore, while we used ICU admission and hospital LOS as proxies for stroke severity, other unmeasured confounders could have affected the regression results. As we excluded patients who died or were discharged from rehabilitation departments, patients included in our study may have milder stroke or different distribution of risk factors. Future studies could also examine the use of antihypertensive therapy which could be beneficial for haemorrhagic stroke patients.

\section{Conclusion}

Among first-ever stroke patients admitted to 2 tertiary hospitals in Singapore between 2010-2014, the observed temporal trends in medication prescribing could be explained by guideline changes, publication of new evidence and availability of generic drugs. In ischaemic stroke, the increased combined utilisation of all 3 guideline medications was due to increased prescription of thrombolytic therapy, oral antithrombotics and statins. There was a trend for a switch from low-intensity statins to atorvastatin, and from single antiplatelet to dual antiplatelet combination during the acute stroke hospitalisation. Similarly, anticoagulation use had increased-specifically prescription of the DOACs among AF patients. Patient characteristics associated with use of all 3 guideline medications included age, ethnicity and certain comorbidities (hyperlipidaemia, $\mathrm{AF}$ and $\mathrm{CKD}$ ). Prescription of statins in haemorrhagic stroke were expectedly lower, as they are not routinely recommended except for patients with comorbidities such as hyperlipidaemia and CHD. Additional information such as stroke severity should be included in future research examining predictors of drug utilisation.

\section{Acknowledgements}

The authors would like to thank Daveon Yu Kai Liu from the National Healthcare Group, Singapore for data extraction. See-Hwee Yeo was supported by the National University of Singapore Industry-Relevant PhD Scholarship.

\section{REFERENCES}

1. Kernan WN, Ovbiagele B, Black HR, Bravata DM, Chimowitz MI, Ezekowitz MD, et al. Guidelines for the prevention of stroke in patients with stroke and transient ischemic attack: a guideline for healthcare professionals from the American Heart Association/American Stroke Association. Stroke 2014;45:2160-236.

2. Jauch EC, Saver JL, Adams HP Jr, Bruno A, Connors JJ, Demaerschalk $\mathrm{BM}$, et al. Guidelines for the early management of patients with acute ischemic stroke: a guideline for healthcare professionals from the American Heart Association/American Stroke Association. Stroke 2013;44:870-947.

3. Stone NJ, Robinson JG, Lichtenstein AH, Bairey Merz CN, Blum CB, Eckel RH, et al. 2013 ACC/AHA guideline on the treatment of blood cholesterol to reduce atherosclerotic cardiovascular risk in adults: a report of the American College of Cardiology/American Heart Association Task Force on Practice Guidelines. Circulation 2014;129:S1-45.

4. Connolly ES Jr, Rabinstein AA, Carhuapoma JR, Derdeyn CP, Dion J, Higashida RT, et al. Guidelines for the management of aneurysmal subarachnoid hemorrhage: a guideline for healthcare professionals from the American Heart Association/American Stroke Association. Stroke 2012;43:1711-37.

5. Hemphill JC $3^{\text {rd }}$, Greenberg SM, Anderson CS, Becker K, Bendok BR, Cushman M, et al. Guidelines for the management of spontaneous intracerebral hemorrhage: a guideline for healthcare professionals from the American Heart Association/American Stroke Association. Stroke 2015;46:2032-60.

6. Dippel DW, Simoons ML. Improving adherence to guidelines for acute stroke management. Circulation 2009;119:16-8.

7. Sacco RL, Gardener H, Wang K, Dong C, Ciliberti-Vargas MA, Gutierrez $\mathrm{CM}$, et al. Racial-ethnic disparities in acute stroke care in the FloridaPuerto Rico Collaboration to Reduce Stroke Disparities Study. JAm Heart Assoc 2017;6:e004073.

8. Canavero I, Cavallini A, Perrone P, Magoni M, Sacchi L, Quaglini S, et al. Clinical factors associated with statins prescription in acute ischemic stroke patients: findings from the Lombardia Stroke Registry. BMC Neurol 2014;14:53.

9. Kim BJ, Park JM, Kang K, Lee SJ, Ko Y, Kim JG, et al. Case characteristics, hyperacute treatment, and outcome information from the clinical research center for Stroke - Fifth Division Registry in South Korea. J Stroke 2015;17:38-53.

10. Hsieh FI, Lien LM, Chen ST, Bai CH, Sun MC, Tseng HP, et al. Get With the Guidelines-Stroke performance indicators: surveillance of stroke care in the Taiwan Stroke Registry: Get With the Guidelines-Stroke in Taiwan. Circulation 2010;122:1116-23.

11. Fabiana N, Ramaswami AP, Ang ES, De Silva DA. Underutilisation of guideline-based therapy primary prevention among patients presenting with AF-related ischaemic stroke. Ann Acad Med Singapore 2015;44:266-8.

12. Toh MP, Leong HS, Lim BK. Development of a diabetes registry to improve quality of care in the National Healthcare Group in Singapore. Ann Acad Med Singapore 2009;38:546-51.

13. Ministry of Health, Singapore. Hospital Services. 2018. Available at: https:/www.moh.gov.sg/our-healthcare-system/healthcare-services-andfacilities/hospital-services. Accessed on 17 June 2019.

14. Nagaraja N, Adams HP, Jr. Alteplase in acute ischemic stroke: putting the guidelines into practice. CNS Drugs 2014;28:1035-45.

15. Adams HP Jr, del Zoppo G, Alberts MJ, Bhatt DL, Brass L, Furlan A, et al. Guidelines for the early management of adults with ischemic stroke: a guideline from the American Heart Association/American Stroke Association Stroke Council, Clinical Cardiology Council, Cardiovascular Radiology and Intervention Council, and the Atherosclerotic Peripheral Vascular Disease and Quality of Care Outcomes in Research Interdisciplinary Working Groups. Stroke 2007;38:1655-711. 
16. De Silva DA, Yassin N, Toh AJ, Lim DJ, Wong WX, Woon FP, et al. Timing of arrival to a tertiary hospital after acute ischaemic stroke: a follow-up survey 5 years later. Ann Acad Med Singapore 2010;39:513-5.

17. Hacke W, Kaste M, Bluhmki E, Brozman M, Dávalos A, Guidetti D, et al. Thrombolysis with alteplase 3 to 4.5 hours after acute ischemic stroke. N Engl J Med 2008;359:1317-29.

18. Del Zoppo GJ, Saver JL, Jauch EC, Adams HP Jr, American Heart Association Stroke Council. Expansion of the time window for treatment of acute ischemic stroke with intravenous tissue plasminogen activator: a science advisory from the American Heart Association/American Stroke Association. Stroke 2009;40:2945-8.

19. Ministry of Health, Singapore. MOH Clinical Guidance: Use of Intravenous Recombinant Tissue Plasminogen Activator (rtPA) in Ischaemic Stroke Patients. 2013. Available at: https://www.moh.gov. sg/docs/librariesprovider4/guidelines/gc0082 moh clinical-guidance_ finalsendpdf.pdf. Accessed on 17 June 2019.

20. Mohan KM, Wolfe CD, Rudd AG, Heuschmann PU, Kolominsky-Rabas PL, Grieve AP. Risk and cumulative risk of stroke recurrence: a systematic review and meta-analysis. Stroke 2011;42:1489-94.

21. Adams RJ, Albers G, Alberts MJ, Benavente O, Furie K, Goldstein LB, et al. Update to the AHA/ASA recommendations for the prevention of stroke in patients with stroke and transient ischemic attack. Stroke 2008;39:1647-52.

22. Wang Y, Wang Y, Zhao X, Liu L, Wang D, Wang C, et al. Clopidogrel with aspirin in acute minor stroke or transient ischemic attack. N Engl J Med 2013;369:11-9.

23. Ko DT, Krumholz HM, Tu JV, Austin PC, Stukel TA, Koh M, et al. Clinical outcomes of plavix and generic clopidogrel for patients hospitalized with an acute coronary syndrome. Circ Cardiovasc Qual Outcomes 2018;11:e004194.

24. Secondary prevention in non-rheumatic atrial fibrillation after transient ischaemic attack or minor stroke. EAFT (European Atrial Fibrillation Trial) Study Group. Lancet 1993;342:1255-62.

25. ACTIVE Writing Group of the ACTIVE Investigators, Connolly S, Pogue J, Hart R, Pfeffer M, Hohnloser S, et al. Clopidogrel plus aspirin versus oral anticoagulation for atrial fibrillation in the Atrial fibrillation Clopidogrel Trial with Irbesartan for prevention of Vascular Events (ACTIVE W): a randomised controlled trial. Lancet 2006;367:1903-12.

26. EissaA, Krass I, Bajorek BV. Use of medications for secondary prevention in stroke patients at hospital discharge in Australia. Int J Clin Pharm 2014;36:384-93.

27. Fonarow GC, Reeves MJ, Smith EE, Saver JL, Zhao X, Olson DW, et al. Characteristics, performance measures, and in-hospital outcomes of the first one million stroke and transient ischemic attack admissions in Get With the Guidelines-Stroke. Circ Cardiovasc Qual Outcomes 2010;3:291-302.

28. Chen $\mathrm{CH}$, Chen MC, Gibbs H, Kwon SU, Lo S, On YK, et al. Antithrombotic treatment for stroke prevention in atrial fibrillation: the Asian agenda. Int J Cardiol 2015;191:244-53.

29. Chao TF, Chen SA. Stroke and bleeding risk in Asians with atrial fibrillation. 2016. Available at: https://www.acc.org/latest-in-cardiology/ articles/2016/03/14/07/27/stroke-and-bleeding-risk-in-asians-with-atrialfibrillation. Accessed on 6 July 2019.

30. Furie KL, Goldstein LB, Albers GW, Khatri P, Neyens R, Turakhia MP, et al. Oral antithrombotic agents for the prevention of stroke in nonvalvular atrial fibrillation: a science advisory for healthcare professionals from the American Heart Association/American Stroke Association. Stroke 2012;43:3442-53
31. Bauer KA. Pros and cons of new oral anticoagulants. Hematology Am Soc Hematol Educ Program 2013;2013:464-70.

32. Ministry of Health, Singapore. Drug Subsidies and Schemes. 2019. Available at: https://www.moh.gov.sg/cost-financing/healthcare-schemessubsidies/drug-subsidies-schemes. Accessed on 6 July 2019.

33. Ganetsky M, Babu KM, Salhanick SD, Brown RS, Boyer EW. Dabigatran: review of pharmacology and management of bleeding complications of this novel oral anticoagulant. J Med Toxicol 2011;7:281-7.

34. Huber K, Connolly SJ, Kher A, Christory F, Dan GA, Hatala R, et al. Practical use of dabigatran etexilate for stroke prevention in atrial fibrillation. Int J Clin Pract 2013;67:516-26.

35. Lin KJ, Hernandez-Diaz S, Garcia Rodriguez LA. Acid suppressants reduce risk of gastrointestinal bleeding in patients on antithrombotic or anti-inflammatory therapy. Gastroenterology 2011;141:71-9.

36. Schaefer JK, McBane RD, Wysokinski WE. How to choose appropriate direct oral anticoagulant for patient with nonvalvular atrial fibrillation. Ann Hematol 2016;95:437-49.

37. Furie KL, Kasner SE, Adams RJ, Albers GW, Bush RL, Fagan SC, et al. Guidelines for the prevention of stroke in patients with stroke or transient ischemic attack: a guideline for healthcare professionals from the American Heart Association/American Stroke Association. Stroke 2011;42:227-76

38. Loch A, Bewersdorf JP, Kofink D, Ismail D, Abidin IZ, Veriah RS. Generic atorvastatin is as effective as the brand-name drug (LIPITOR $\AA$ ) in lowering cholesterol levels: a cross-sectional retrospective cohort study. BMC Res Notes 2017;10:291.

39. Wolfe S. Rosuvastatin: winner in the statin wars, patients' health notwithstanding. BMJ 2015;350:h1388.

40. United States Food and Drug Administration. FDA Drug Safety Communication: New Restrictions, Contraindications and Dose Limitations for Zocor (Simvastatin) to Reduce the Risk of Muscle Injury. 2011. Available at: https://www.fda.gov/Drugs/DrugSafety/ucm256581. htm. Accessed on 6 July 2019.

41. Health Sciences Authority, Singapore. Safety Updates on Statins. 2012. Available at: https://www.hsa.gov.sg/content/hsa/en/Health Products Regulation/Safety Information and Product Recalls/Product Safety Alerts/2012/24_aug_2012_safety.html. Accessed on 6 July 2019.

42. Faigle R, Urrutia VC, Cooper LA, Gottesman RF. Individual and system contributions to race and sex disparities in thrombolysis use for stroke patients in the United States. Stroke 2017;48:990-7.

43. Aparicio HJ, Carr BG, Kasner SE, Kallan MJ, Albright KC, Kleindorfer $\mathrm{DO}$, et al. Racial disparities in intravenous recombinant tissue plasminogen activator use persist at primary stroke centers. J Am Heart Assoc 2015;4:e001877.

44. Kimball MM, Neal D, Waters MF, Hoh BL. Race and income disparity in ischemic stroke care: nationwide inpatient sample database, 2002 to 2008. J Stroke Cerebrovasc Dis 2014;23:17-24.

45. Tuhrim S, Cooperman A, Rojas M, Brust JC, Koppel B, Martin K, et al. The association of race and sex with the underuse of stroke prevention measures. J Stroke Cerebrovasc Dis 2008;17:226-34.

46. Department of Statistics, Singapore. General Household Survey (GHS), 2015.Available at: https://www.singstat.gov.sg/-/media/files/publications/ ghs/ghs2015/ghs2015.pdf. Accessed on 6 July 2019.

47. Sung SF, Chen SC, Hsieh CY, Li CY, Lai EC, Hu YH. A comparison of stroke severity proxy measures for claims data research: a populationbased cohort study. Pharmacoepidemiol Drug Saf 2016;25:438-43. 
Supplementary Table 1. International Classification of Diseases $9^{\text {th }}$ Revision Clinical Modification Codes Used for Case Identification

\begin{tabular}{ll}
\hline Code & Description \\
\hline 430 & Subarachnoid haemorrhage \\
\hline 431 & Intracerebral haemorrhage \\
\hline 433.11 & Occlusion and stenosis of carotid artery with cerebral infarction \\
\hline 433.21 & Occlusion and stenosis of vertebral artery with cerebral infarction \\
\hline 433.31 & Occlusion and stenosis of multiple and bilateral precerebral arteries with cerebral infarction \\
\hline 434.01 & Cerebral thrombosis with cerebral infarction \\
\hline 434.11 & Cerebral embolism with cerebral infarction \\
\hline 434.91 & Cerebral artery occlusion, unspecified with cerebral infarction \\
437.1 & Other generalised ischaemic cerebrovascular disease \\
\hline
\end{tabular}

Supplementary Table 2. International Classification of Diseases $10^{\text {th }}$ Revision Australian Modification Codes Used for Case Identification

\begin{tabular}{|c|c|}
\hline Code & Description \\
\hline I60.0 & Subarachnoid haemorrhage from carotid siphon and bifurcation \\
\hline I60.1 & Subarachnoid haemorrhage from middle cerebral artery \\
\hline I60.2 & Subarachnoid haemorrhage from anterior communicating artery \\
\hline I60.3 & Subarachnoid haemorrhage from posterior communicating artery \\
\hline I60.4 & Subarachnoid haemorrhage from basilar artery \\
\hline I60.6 & Subarachnoid haemorrhage from other intracranial arteries \\
\hline I60.7 & Subarachnoid haemorrhage from intracranial artery, unspecified \\
\hline I60.8 & Other subarachnoid haemorrhage \\
\hline I60.9 & Subarachnoid haemorrhage, unspecified \\
\hline I61.0 & Intracerebral haemorrhage in hemisphere, subcortical \\
\hline $\mathrm{I} 61.2$ & Intracerebral haemorrhage in hemisphere, unspecified \\
\hline I61.3 & Intracerebral haemorrhage in brain stem \\
\hline I61.4 & Intracerebral haemorrhage in cerebellum \\
\hline I61.5 & Intracerebral haemorrhage, intraventricular \\
\hline I61.8 & Other intracerebral haemorrhage \\
\hline I61.9 & Intracerebral haemorrhage, unspecified \\
\hline I63.0 & Cerebral infarction due to thrombosis of precerebral arteries \\
\hline I63.1 & Cerebral infarction due to embolism of precerebral arteries \\
\hline I63.2 & Cerebral infarction due to unspecified occlusion or stenosis of precerebral arteries \\
\hline I63.3 & Cerebral infarction due to thrombosis of cerebral arteries \\
\hline I63.4 & Cerebral infarction due to embolism of cerebral arteries \\
\hline I63.5 & Cerebral infarction due to unspecified occlusion or stenosis of cerebral arteries \\
\hline I63.8 & Other cerebral infarction \\
\hline I63.9 & Cerebral infarction, unspecified \\
\hline I66.0 & Occlusion and stenosis of middle cerebral artery \\
\hline I66.2 & Occlusion and stenosis of posterior cerebral artery \\
\hline I66.3 & Occlusion and stenosis of cerebellar arteries \\
\hline I66.8 & Occlusion and stenosis of other cerebral artery \\
\hline I66.9 & Occlusion and stenosis of unspecified cerebral artery \\
\hline
\end{tabular}


Supplementary Table 3. International Classification of Diseases $9^{\text {th }}$ Revision Clinical Modification Codes Used for Case Exclusion

\begin{tabular}{ll}
\hline Code & Description \\
\hline 436 & Acute, but ill-defined, cerebrovascular disease \\
\hline 437 & Other and ill-defined cerebrovascular disease \\
\hline 437.5 & Moyamoya disease \\
\hline 437.6 & Non-pyogenic thrombosis of intracranial venous sinus \\
\hline 437.8 & Other ill-defined cerebrovascular disease \\
\hline 437.9 & Unspecified cerebrovascular disease \\
\hline
\end{tabular}

Supplementary Table 4. International Classification of Diseases $10^{\text {th }}$ Revision Australian Modification Codes Used for Case Exclusion

\begin{tabular}{ll}
\hline Code & Description \\
\hline I62.1 & Non-traumatic extradural haemorrhage \\
\hline I64 & Stroke, not specified as haemorrhage or infarction \\
\hline I67.5 & Moyamoya disease \\
\hline I67.6 & Non-pyogenic thrombosis of intracranial venous system \\
\hline I67.8 & Other specified cerebrovascular diseases \\
\hline I67.9 & Cerebrovascular disease, unspecified \\
\hline
\end{tabular}

Supplementary Table 5. Drug Classes and Specific Drugs Included in Study

\begin{tabular}{lll}
\hline Drug Class & Specific Drug \\
\hline Thrombolytic agents & Alteplase \\
\hline Antiplatelets & Aspirin \\
\hline & Clopidogrel \\
\hline & Dipyridamole \\
\hline Ticlopidine \\
\hline Oral anticoagulants & Apixaban \\
\hline & Dabigatran \\
\hline Parenteral anticoagulants & Rexaroxan \\
\hline & Warfarin \\
\hline Statins & Enoxaparin \\
\hline & Nadroparin \\
\hline & Atorvastatin \\
\hline & Lovastatin \\
\hline & Pravastatin \\
\hline & Rosuvastatin \\
\hline
\end{tabular}

